\title{
Do muscle strengthening exercises improve performance in the 6-minute walk test in postmenopausal women?
}

\section{O exercício de força muscular é eficiente para melhorar o desempenho no teste de caminhada de 6 minutos em mulheres pós-menopausais?}

Júlia G. Reis', Gustavo C. Costa', André Schmidt², Cristine H. J. Ferreira', Daniela C. C. Abreu'

\begin{abstract}
Background: Walking speed seems to be related to aerobic capacity, lower limb strength, and functional mobility, however it is not clear whether there is a direct relationship between improvement in muscle strength and gait performance in early postmenopausal women. Objective: To evaluate the effect of muscle strengthening exercises on the performance of the 6-minute walk test in women within 5 years of menopause. Methods: The women were randomized into control group $(n=31)$, which performed no exercise, and exercise group $(n=27)$, which performed muscle strengthening exercises. The exercises were performed twice a week for 3 months. The exercise protocol consisted of warm-up, stretching, and strengthening of the quadriceps, hamstring, calf, tibialis anterior, gluteus maximus, and abdominal muscles, followed by relaxation. Muscular strength training started with $60 \%$ of $1 \mathrm{MR}$ ( 2 series of $10-15$ repetitions), reaching $85 \%$ until the end of the 3-month period (4 series of 6 repetitions each). Results: The between-group comparisons pre- and post-intervention did not show any difference in distance walked, heart rate or blood pressure ( $p>0.05)$, but showed differences in muscle strength post-intervention, with the exercise group showing greater strength $(p<0.05)$. In the within-group comparison, there were differences in final heart rate and quadriceps and hamstring strength pre- and post-intervention in the exercise group $(p<0.05)$. Conclusion: The results suggest that muscle strengthening of the lower limbs did not improve performance in the 6-minute walk test in this population of postmenopausal women. Trial registration ACTRN12609001053213
\end{abstract}

Keywords: physical therapy; post-menopause; exercise program; muscle strength; 6-minute walk test.

\section{Resumo}

Contextualização: A velocidade de marcha parece estar relacionada com a capacidade aeróbica, força dos músculos dos membros inferiores e mobilidade funcional. Entretanto, não está claro se existe uma relação direta entre a melhora da força muscular e o desempenho da marcha em mulheres pós-menopausais recentes. Objetivo: Avaliar o efeito de exercícios de fortalecimento muscular sobre o desempenho no teste de caminhada de 6 minutos em mulheres nos primeiros cinco anos após a menopausa. Métodos: As mulheres foram randomizadas em grupo controle ( $n=31)$, que não realizou exercício, e grupo exercício $(n=27)$, que realizou um programa de exercícios. O programa de exercícios foi realizado duas vezes por semana, durante três meses, e consistiu em aquecimento, alongamento, exercícios de fortalecimento muscular para quadríceps, isquiotibiais, tríceps sural, tibial anterior, glúteo máximo e abdominais, finalizando com relaxamento. O treinamento de força iniciou com 60\% de 1RM (duas séries de 10-15 repetições) e atingiu 85\% (quatro séries de seis repetições) no final dos três meses. Resultados: As comparações entre os grupos pré e pós-três meses não mostraram diferenças para distância percorrida, frequência cardíaca (FC) e pressão arterial $(p \geq 0,05)$, mas mostraram diferenças para força muscular após três meses, com o grupo exercício apresentando maior força $(p \leq 0,05)$. Nas comparações antes e após três meses intragrupos, houve diferenças para FC, forças musculares de quadríceps e isquiotibiais para o grupo intervenção. Conclusão: Os resultados sugerem que o treinamento de força muscular dos membros inferiores não melhora o teste de caminhada de 6 minutos para essa população de mulheres avaliadas. Registro de Ensaio Clínico ACTRN12609001053213.

Palavras-chave: fisioterapia; pós-menopausa; programa de exercícios; força muscular; teste de caminhada de 6 minutos.

Received: 08/08/2011 - Revised: 11/07/2011 - Accepted: 12/21/2011

${ }^{1}$ Physical Therapy Course, Department of Biomechanics, Medicine, and Rehabilitation of the Locomotor System, Faculdade de Medicina de Ribeirão Preto (FMPR), Universidade de São Paulo (USP), Ribeirão Preto, SP, Brazil

${ }^{2}$ Cardiology Division, FMRP, USP, Ribeirão Preto, SP, Brazil

Correspondence to: Daniela Cristina Carvalho de Abreu, Departamento de Biomecânica, Medicina e Reabilitação do Aparelho Locomotor, FMRP/USP, Av. Bandeirantes, 3900, CEP 14049-900 Ribeirão Preto, SP, Brasil, e-mail: dabreu@fmrp.usp.br 


\section{Introduction $: \therefore$.}

The aging process involves several changes in the body, including progressive reduction in muscular strength with connective and fatty tissue replacement, as well as a decrease in the amount of physical activity ${ }^{1}$. Studies have suggested that the decreased muscular strength in women over 50 may be related to a lack of the hormone estrogen resulting from menopause $e^{2-3}$.

There are also reports that a higher incidence of cardiovascular disease is one of the co-morbidities associated with climacteric hypoestrogenism ${ }^{4}$. Studies have shown negative effects of hypoestrogenism on heart rate (HR) variability ${ }^{5-6}$, which is influenced by sympathetic and parasympathetic activity. The efferent sympathetic system increases HR, whereas the efferent parasympathetic system reduces it ${ }^{7}$. Thus, the high performance of the sympathetic system during rest becomes harmful to the heart and increases the risk of cardiovascular disease ${ }^{8}$.

Therefore, exercise programs aimed at preventing the health problems that are prevalent after menopause are very important. Some studies have demonstrated that muscular strengthening exercises in elderly individuals can have a positive effect on their functionality and independence ${ }^{9-10}$. Tanasescu et al. ${ }^{11}$ and Taylor et al. ${ }^{12}$ observed that strength training is beneficial to individuals at high risk for coronary heart disease. Also, Tyni-Lenné et al. ${ }^{13}$ observed that local muscle training improved aerobic and functional capacity in patients with chronic heart failure. However, it is not clear what impact these muscle training protocols have on the aerobic capacity of middle-aged postmenopausal women. Knowledge about the complete effect of exercise programs on body systems is important to develop appropriate interventions for the specific needs of the patients.

The 6-minute walk test (6MWT), originally developed to evaluate aerobic capacity in patients with respiratory diseases $^{14}$, is currently being used in healthy individuals ${ }^{15-16}$ to evaluate functional performance during the daily activity of walking ${ }^{17}$. To perform this rapid and simple sub-maximum effor $^{16}$ in which the subject walks as quickly as possible for 6 minutes, several systems are required such as the cardiorespiratory, muscular, and osteoarticular systems, and the result depends on the association between all these factors.

Because the 6MWT evaluates functional capacity in daily activities and the increase in muscular strength can benefit functionality, the objective of this study was to evaluate the effect of muscle strengthening exercises on the 6MWT. To achieve that aim, middle-aged postmenopausal women within 5 years of menopause were recruited to perform such exercises twice a week for 3 months.

\section{Methods $: \because$.}

A total of 88 post-menopausal women were recruited from the local community for the study. Thirty women were excluded because they had diabetes mellitus or rheumatic diseases or had undergone hysterectomy. Fifty-eight sedentary women who were physically active once a week or less, not taking hormone replacement therapy (HRT), and within 5 years of menopause (44.11 \pm 15.00 months) were randomly assigned by computer software to Control Group (CG), consisting of 31 women who did not follow the physical exercise protocol, and Exercise Group (EG), consisting of 27 women who performed the physical exercise protocol twice a week for 3 months. Seven women from the CG withdrew from the study due to lack of interest or health problems. Figure 1 shows the flow chart for the participants. The research study was approved by the $\mathrm{Hu}-$ man Research Ethics Committee of the School of Medicine of Ribeirão Preto, Universidade de São Paulo (USP), Ribeirão Preto, SP, Brazil (protocol number 259). All volunteers gave their informed consent before participating in the study.

The criteria for menopause were absence of menstrual cycles for more than 12 consecutive months as defined by the World Health Organization (WHO) and follicle-stimulating hormone $(\mathrm{FSH}) \geq 40 \mathrm{mIU} / \mathrm{ml}$. Exclusion criteria were smoking, hysterectomy, cardiorespiratory, neurologic, and rheumatic diseases, orthopaedic problems, cognitive problems, vestibulopathies, diabetes mellitus, and recent history of bone fractures.

In the beginning of the study, all participants performed the $6 \mathrm{MWT}$ according to the recommendations of the American Thoracic Society ${ }^{14}$. They were advised to avoid alcoholic beverages, coffee, and heavy meals for at least 12 hours before the test. The test was conducted in a 30-metre hallway only once, because the learning effect of the test is not important when using the results as a baseline predictor of later events ${ }^{18}$. The

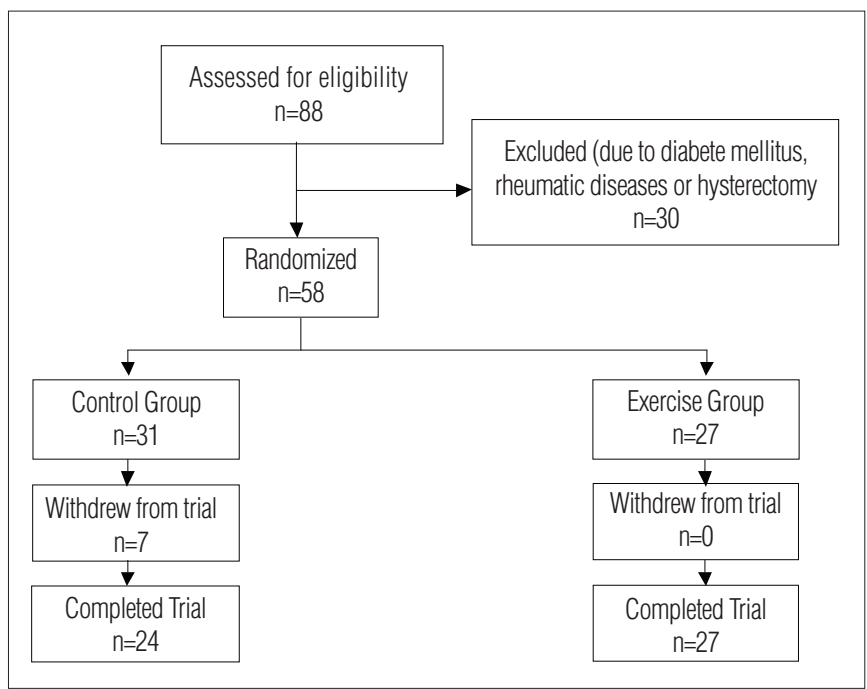

Figure 1. Flow chart for the randomized sample. 
participants were instructed to walk as quickly as possible for six minutes, with a rest break if necessary. Each minute, the investigator encouraged the women to keep on walking by saying standard phrases such as "walk as quickly as you can" and "you're doing very well".

For comparison between groups, blood pressure (BP) and HR were recorded in the beginning and at the end of the $6 \mathrm{MWT}$, the latter being measured with a cardio-frequency meter (Polar, RS800 ${ }^{\mathrm{TM}}$, Finland). The distance walked was also recorded. At the end of the test, the modified Borg Scale was applied to assess the level of fatigue at the end of exercise ${ }^{14}$.

In order to standardise the weights used during the lower limb muscle strengthening exercises, one maximum repetition (1MR) test was applied, which is defined as the greatest load for complete movement amplitude before two unsuccessful attempts. The women performed the muscle strength test 2 days after being submitted to the 6MWT. Before the test, they did a 5-minute warm-up on a leg flexor-extensor machine for each muscle group (quadriceps and hamstring) by means of a series of 8-12 repetitions with minimum load. Next, they performed the $1 \mathrm{MR}$ test on the same machine with progressive load and a 90-120 second rest interval. The participants had 5 attempts to achieve $1 \mathrm{MR}^{19}$.

After the initial evaluation, the EG performed muscle strengthening exercises using ankle weights for 60 minutes, twice a week, for three months. The exercise protocol consisted of warm-up, stretching, and strengthening of the quadriceps, hamstring, calf, tibialis anterior, gluteus maximus, and abdominal muscles, followed by relaxation. The CG did not exercise for 3 months after the initial evaluation, but they were encouraged to continue their routine activities. Muscular strength training started with $60 \%$ of $1 \mathrm{MR}(2$ series of 10-15 repetitions), followed by a 3-week protocol of weight adjustment, progressing to $70 \%, 80 \%$ (3 series of $8-10$ repetitions), and up to $85 \%$ of $1 \mathrm{MR}$ ( 4 series of 6 repetitions each) at the end of the 3-month period. The participants were evaluated by investigator \#1, and the exercise protocol was applied by investigator \#2. The first investigator was blinded to group allocation.

By using the Shapiro-Wilk normality test and Levene's test for variance homogeneity, we found that the mean values for all variables met the presumptions required for applying univariate and multivariate analyses. As a result, nine MANOVAs and six ANOVAs were performed. Three MANOVAs were performed with group (exercise and control) as factor. The first MANOVA had initial and final HR as dependent variables; the second MANOVA had initial and final systolic BP and diastolic BP as dependent variables; and the third MANOVA had quadriceps and hamstring muscle strength as dependent variables. The other MANOVAs were performed with time (pre- and post-intervention) as factor, and this was treated as a repeated measurement. The fourth and fifth MANOVAs had initial and final HR as dependent variables; the sixth and seventh MANOVAs had initial and final systolic and diastolic BP as dependent variables; and the eighth and ninth MANOVAs had quadriceps and hamstring muscle strength as dependent variables for EG and CG, respectively. Four of the six ANOVAs were performed with group as factor. The first ANOVA had age as dependent variable, whereas body mass, body height, and walked distance were the dependent variables for the second, third, and fourth ANOVAs. The other ANOVAs had time (pre- and post-intervention) as factor, and this was treated as a repeated measurement. The fifth and sixth ANOVAs had walked distance as dependent variable for EG and CG, respectively. All statistical analyses were carried out with the software SPSS 10.0 for Windows (SPSS Inc., USA) at significance level of 0.05.

\section{Results : :}

The CG had mean age of $53.86 \pm 5.11$ years, mean height of $1.56 \pm 0.06 \mathrm{~m}$, and mean weight of $73.31 \pm 12.81 \mathrm{~kg}$, whereas those of the EG had mean age of $52.91 \pm 4.02$ years, mean height of $1.55 \pm 0.07 \mathrm{~m}$, and mean weight of $68.66 \pm 12.81 \mathrm{~kg}$. No significant differences ( $p>0.05$ ) were found between both groups regarding the anthropometric variables.

Table 1 shows data obtained from the 6MWT and muscle strength test performed in the beginning of the study and after three months for the CG and EG.

No statistical differences were found between-group comparison for the variables BP, HR, and walked distance by comparing the initial and final values. In the within-group comparison, MANOVA showed no effect on walked distance pre- and post-intervention in the CG [Wilks' lambda $=0.83$, $\mathrm{F}(1,13)=2.64, \mathrm{p}>0.05$ ] and the EG [Wilks' lambda=0.91, $\mathrm{F}(1,22)=2.04, \mathrm{p}>0.05]$. Both groups had no differences between walked distance post-intervention.

The CG achieved $79 \%$ of maximum HR during the pre-intervention test and $78 \%$ post-intervention. The EG achieved $74 \%$ of maximum HR in the pre-intervention test, with $79 \%$ post-intervention. The within-group comparison revealed an effect on HR pre- and post-intervention in the EG [Wilks' lambda=0.94, $\mathrm{F}(2,21)=0.66, \mathrm{p}<0.05]$. Univariate analyses showed that the EG had greater final HR post-intervention $[\mathrm{F}(1,22)=7.68, \mathrm{p}<0.05]$.

The between-group comparison for muscle strength data at baseline did not show any differences $(p>0.05)$. The betweengroup comparison for muscle strength revealed an effect on final muscle strength [Wilks' lambda=0.84, $\mathrm{F}(2,34)=3.33, \mathrm{p}<0.05$ ], and univariate analyses showed that the EG had greater quadriceps strength $[\mathrm{F}(1,35)=7.80, \mathrm{p}<0.05]$ and hamstrings strength $[\mathrm{F}(1,35)=6.83, \mathrm{p}<0.05]$ post-intervention. 
Table 1. Data regarding the 6-minute walk test and muscle strengthening performed by both groups in the beginning of the study and after 3 months. Data are expressed in mean values \pm SD (standard deviation).

\begin{tabular}{lcccc} 
& & Baseline & & \multicolumn{2}{c}{ After 3 months } \\
& Control Group & Exercise Group & Control Group & \multicolumn{2}{c}{ Exercise Group } \\
\hline Initial SBP $(\mathrm{mmHg})$ & $124.28 \pm 10.98$ & $119.56 \pm 12.96$ & $122.86 \pm 18.16$ & $119.56 \pm 14.60$ \\
\hline Final SBP $(\mathrm{mmHg})$ & $150.71 \pm 17.74$ & $142.82 \pm 15.28$ & $150.71 \pm 16.39$ & $150 \pm 19.30$ \\
\hline Initial DBP $(\mathrm{mmHg})$ & $81.42 \pm 9.49$ & $80.87 \pm 7.92$ & $80 \pm 12.4$ & $79.13 \pm 7.92$ \\
\hline Final DBP $(\mathrm{mmHg})$ & $83.57 \pm 11.50$ & $84.34 \pm 7.87$ & $87.85 \pm 9.75$ & $83.91 \pm 9.41$ \\
\hline Initial HR (bpm) & $75 \pm 10.61$ & $74.74 \pm 12.05$ & $73 \pm 8.90$ & $12.78 \pm 12.45$ \\
\hline Final HR (bpm) & $132.64 \pm 19.61$ & $123.60 \pm 18.22$ & $131.64 \pm 19.73$ & $132.43 \pm 17.37$ \\
\hline Walked Distance $(\mathrm{m})$ & $569.43 \pm 62.74$ & $535.30 \pm 82.59$ & $549.64 \pm 61.35$ & $556.65 \pm 52.43$ \\
\hline Borg scale & $4.35 \pm 1.98$ & $4.06 \pm 2.28$ & $3.43 \pm 2.14$ & $3.78 \pm 2.08$ \\
\hline Quadriceps strength $(\mathrm{Kg})$ & $8.43 \pm 1.08$ & $7.43 \pm 0.59$ & $8.93 \pm 1.44$ & $13.91 \pm 1.08$ \\
\hline Hamstring strength $(\mathrm{Kg})$ & $6.00 \pm 0.46$ & $6.09 \pm 0.51$ & $6.86 \pm 0.62$ & $8.96 \pm 0.50$ \\
\hline
\end{tabular}

$\mathrm{SBP}=$ systolic blood pressure; $\mathrm{DBP}=$ diastolic blood pressure; HR=heart rate. Quadriceps and hamstring strength values of right lower limb.

The within-group comparison found an effect on muscle strength pre- and post-intervention in the EG [Wilks' lambda $=0.21, \mathrm{~F}(2,21)=39.39, \mathrm{p}<0.05]$. Univariate analyses showed that the EG had greater quadriceps strength $[F(1,22)=49.88$, $\mathrm{p}<0.05]$ and hamstring strength $[\mathrm{F}(1,22)=47.80, \mathrm{p}<0.05]$ postintervention. After three months, no significant differences ( $p>0.05$ ) in HR and muscle strength were found between initial and final results for the CG (women performing no exercise).

\section{Discussion $: \because$ 。}

The results have shown that the women recruited for the present study walked distances of $569.43 \pm 62.74 \mathrm{~m}$ and $535.30 \pm 82.59 \mathrm{~m}$ for the $\mathrm{CG}$ and $\mathrm{EG}$, respectively. After 3 months, the distances were $549.64 \pm 61.35 \mathrm{~m}$ for the $\mathrm{CG}$ and $556.65 \pm 52.43 \mathrm{~m}$ for the EG, with no significant difference between initial and final values $(p>0.05)$. These values are lower than those found by Camarri et al. ${ }^{15}$, who found that women aged 55 to 75 years old had walked $603 \pm 60 \mathrm{~m}$ in the first attempt and $623 \pm 57 \mathrm{~m}$ in the second, with no significant difference between them, reaching approximately $80 \%$ of maximum HR.

It is important to emphasize that, although the population of the study by Camarri et al. ${ }^{15}$ was older compared to this study (range between 43 and 59 years), the distance walked was longer despite the fact that the women in the present study had performed the 6MWT at 74-79\% of the maximum HR, with similar effort levels. In contrast, Chetta et al. ${ }^{16}$ evaluated women with ages ranging from 20 to 50 years who reached a distance of $593 \pm 57 \mathrm{~m}$ with $68 \%$ of maximum HR. This distance was shorter than that found by Camarri et al. ${ }^{15}$, but with less effort. A study conducted by Enright and Sherril ${ }^{18}$ showed a mean distance of $494 \mathrm{~m}$ for women aged between 40 and 80 years, with less than $65 \%$ of maximum HR. This distance was shorter than that found in the present study.
Although it is difficult to set reference values for a healthy adult population because of the particular characteristics found in different populations, the present study evaluated healthy women belonging to a more homogenous age group, since they were middle-aged postmenopausal women within 5 years of menopause (none of them were elderly). Additionally, the women recruited for the study were all sedentary, which probably affected the values obtained here. Some studies have shown that the distance walked during the 6MWT is shorter for older and heavier individuals ${ }^{16,18,20,21}$. Conversely, other studies found no correlation between age and weight for the 6MWT, thus suggesting that health problems and plantar flexor strength may have a greater influence than age itself ${ }^{15,22}$.

In the EG, there was an increase in the final HR after 3 months of exercise. Mercuro et al. ${ }^{5}$ and Liu, Kuo and Yang ${ }^{6}$ found an influence of hypoestrogenism due to menopause in the autonomic nervous system, with a predominance of sympathetic activity. Possibly, the increase in HR in the EG was due to the inclusion of postmenopausal women who were not taking HRT. Additional studies should be carried out to better understand the impact of exercise programs on HR in early postmenopausal women.

Roberts, Li and Sykes $^{23}$ observed that the peak HR of thirty patients with stable ischemic heart disease (mean age $62.1 \pm 8.5$ years) in the 6MWT increased after an 8-week aerobic training program (three times per week for 20 minutes at a time). Before training, the mean peak HR value was $105 \mathrm{bpm}$ versus $110 \mathrm{bpm}$ after training $(\mathrm{p}<0.05)$. However, most studies that evaluated the cardiovascular effects of physical training found no difference in maximal $\mathrm{HR}$ after training ${ }^{24-25}$.

The aging process promotes a gradual decrease in both muscle mass and muscle strength, with an estimated 5\% loss in muscle mass every decade after age 40 , affecting mainly the lower limbs, with greater decline after 65 years of age ${ }^{26}$. Landers et al..$^{27}$ cited that the reduction in quadriceps strength is one of 
the causes of poor performance in activities such as walking, sitting/standing, and going up/down stairs, which in turn may interfere with performance in the walk test ${ }^{18}$. Based on this context, a muscle strengthening protocol may improve performance in the 6MWT, thus increasing the distance walked.

In the EG, there was improvement in lower limb muscle strength post-intervention. Several studies emphasize the importance of strengthening exercises in training protocols for postmenopausal women ${ }^{28,29}$ because they are effective in increasing muscle strength and endurance in these women.

The results showed that the increase in quadriceps and hamstring strength had no effect on the distance reached by the early postmenopausal women during the 6MWT. It is possible that this muscle strengthening protocol would yield a more favorable result on gait performance for older individuals, since this population already has a natural decline in muscle strength.

In summary, this study demonstrated that a 3-month exercise protocol for strengthening lower limb muscles promoted an increase in muscle strength, but not in the distance walked in the 6MWT in a female population with mean age of $53.20 \pm 4.4$ years. These results suggest that muscle strength training alone may not be the best alternative when the training goal is to increase the functional mobility or the aerobic capacity of early postmenopausal women. The limitations of the present study were the small sample, the lack of strength evaluations of other muscles such as the calf muscle and tibialis anterior, and the duration of the strengthening program (only 3 months).

\section{Acknowledgements ::}

To the Bioengineering Unit of the School of Medicine of Ribeirão Preto, USP, to Fundação de Amparo à Pesquisa do Estado de São Paulo (FAPESP), São Paulo, SP, Brazil (\#2007/54596-0; \#2007/07606-0), and to Financiador de Estudos e Projetos (FINEP), Ribeirão Preto, SP, Brazil (Faepa Process 1230/2005) for their support.

\section{References $: \because$.}

1. Carvalho Filho ET, Papaléo Netto M. Geriatria - fundamentos, clínica e terapêutica. $2^{2}$ ed. São Paulo, SP: Atheneu; 2006

2. Greising SM, Baltgavis KA, Lowe DA, Warren GL. Hormone therapy and sketal muscle strength: a meta-analysis. J Gerontol A Biol Sci Med Sci. 2009;64(10):1071-81.

3. Leitão MB, Lazzoli JK, Oliveira MAB, Nóbrega ACL, Silveira GG, Carvalho T, et al. Posicionamento oficial da Sociedade Brasileira de Medicina do Esporte: atividade física e saúde na mulher. Rev Bras Med Esporte. 2000;6(6):215-20.

4. Archer DF. Premature menopause increases cardiovascular risk. Climacteric. 2009;12 Suppl 1:26-31.

5. Mercuro G, Podda A, Pitzalis L, Zoncu S, Mascia M, Melis GB, et al. Evidence of a role of endogenous estrogen in the modulation of autonomic nervous system. Am J Cardiol. 2000;85(6):787-9.

6. Liu CC, Kuo TBJ, Yang CCH. Effects of estrogen on gender-related autonomic differences in humans. Am J Physiol Heart Circ Physiol. 2003;285(5):H2188-93.

7. Sandercock GRH, Bromley PD, Brodie DA. Effects of exercise on heart rate variability: inferences from meta-analysis. Med Sci Sports Exerc. 2005;37(3):433-9.

8. Gregoire J, Tuck S, Yamamoto Y, Hughson RL. Heart rate variability at rest and exercise: influence of age, gender, and physical training. Can J Appl Physiol. 1996;21(6):455-70.

9. Brill PA, Macera CA, Davis DR, Blair SN, Gordon N. Muscular strength and physical function. Med Sci Sports Exerc. 2000;32(2):412-6.

10. Gauchard GC, Gangloff P, Jeandel C, Perrin PP. Physical activity improves gaze and posture control in the elderly. Neurosci Res. 2003;45(4):409-17.

11. Tanasescu M, Leitzmann MF, Rimm EB, Willett WC, Stampfer MJ, Hu FB. Exercise type and intensity in relation to coronary heart disease in men. JAMA. 2002;288(16):1994-2000.

12. Taylor RS, Brown A, Ebrahim S, Jolliffe J, Noorani H, Rees K, et al. Exercise-based rehabilitation for patients with coronary heart disease: systematic review and meta-analysis of randomized controlled trials. Am J Med. 2004;116(10):682-92.

13. Tyni-Lenné R, Dencker K, Gordon A, Jansson E, Sylvén C. Comprehensive local muscle training increases aerobic working capacity and quality of life and decreases neurohormonal activation in patients with chronic heart failure. Eur J Heart Fail. 2001;3(1):47-52.

14. ATS Statement: guidelines for the six-minute walk test. Am J Respir Crit Care Med. 2002:166(1):111-7.

15. Camarri B, Eastwood PR, Cecins NM, Thompson PJ, Jenkins S. Six minute walk distance in healthy subjects aged 55-75 years. Respir Med. 2006;100(4):658-65.
16. Chetta A, Zanini A, Pisi G, Aiello M, Tzani P, Neri M, et al. References values for the 6-min walk test in healthy subjects 20-50 years old. Respir Med. 2006;100(9):1573-8.

17. Bean JF, Kiely DK, Leveille SG, Herman S, Huynh C, Fielding R, et al. The 6-minute walk test in mobility-limited elders: what is being measured? J Gerontol A Biol Sci Med Sci. 2002;57(11):M751-6

18. Enright $P$, Sherrill $D L$. References equations for the six-minute walk in healthy adults. Am J Respir Crit Care Med. 1998;158(5 Pt 1):1384-7.

19. Petrella JK, Kim JS, Tuggle SC, Hall SR, Bamman MM. Age differences in knee extension power, contractile velocity, and fatigability. J Appl Physiol. 2005;98(1):211-20.

20. Gibbons WJ, Fruchter N, Sloan S, Levy RD. Reference values for a multiple repetition 6 -minute walk test in healthy adults older than 20 years. J Cardiopulmonary Rehabil. 2001;21(2):87-93

21. Enright PL. The six-minute walk test. Respir Care. 2003;48(8):783-5.

22. Imms FJ, Edholm OG. Studies of gait and mobility in the elderly. Age Aging. 1981;10(3):147-56.

23. Roberts E, Li FKW, Sykes K. Validity of the 6-minute walk test for assessing heart rate recovery after an exercise-based cardiac rehabilitation programme. Physiotherapy. 2006;92(2):116-21.

24. Ogawa T, Spina RJ, Martin WH 3rd, Kohrt WM, Schechtman KB, Holloszy JO, et al. Effects of aging, sex, and physical training on cardiovascular responses to exercise. Circulation. 1992;86(2):494-503.

25. Perini R, Fischer $\mathrm{N}$, Veicsteinas $\mathrm{A}$, Pendergast DR. Aerobic training and cardiovascular responses at rest and during exercise in older men and women. Med Sci Sports Exerc. 2002;34(4):700-8.

26. Janssen I, Heymsfield SB, Wang ZM, Ross R. Skeletal muscle mass and distribution in 468 men and women aged 18-88 yr. J Appl Physiol. 2000;89(1):81-8.

27. Landers KA, Hunter GR, Wetzstein CJ, Bamman MM, Weinsier RL. The interrelationship among muscle mass, strength and the ability to perform physical tasks of daily living in younger and older women. J Gerontol A Biol Sci Med Sci. 2001;56(10):B443-8.

28. Adams KJ, Swank AM, Berning JM, Sevene-Adams PG, Barnard KL, Shimp-Bowerman J. Progressive strength training in sedentary, older African American women. Med Sci Sports Exerc. 2001;33(9):1567-76.

29. Bemben DA, Fetters NL, Bemben MG, Nabavi N, Koh ET. Musculoskeletal responses to highand low-intensity resistance training in early postmenopausal women. Med Sci Sports Exerc. 2000;32(11):1949-57. 